\title{
Trauma and the Making of Flexible Minds in the Tibetan Exile Community
}

\author{
Sara E. Lewis
}

\begin{abstract}
Mental health in the Tibetan refugee community has been studied extensively, but like most research on political violence, these studies focus almost exclusively on trauma. Studies suggest this exile community seems to be unusually resilient; but from where does this capacity to thrive stem? On the basis of ethnographic research in Dharamsala, India, conducted over 14 months, this article demonstrates how Tibetans conceive of resilience as a learned and active process of making the mind more "spacious" and "flexible." Drawing on extended participant observation and in-depth interviews with 80 Tibetan refugees, this work explores why negative emotions associated with trauma exposure are considered toxic and how many Tibetans exposed to political violence engage in a Buddhist practice known as "mind training" (lojong in Tibetan) to abate its harmful effects. Attending to culturally sanctioned responses to political violence and displacement, this study challenges the notion that trauma is a universal experience. [trauma, resilience, Tibet, Buddhism]
\end{abstract}

Mental health in the Tibetan refugee community has been studied extensively; but like most research on political violence, these studies focus almost exclusively on trauma. We know little about those who manage to thrive in spite of personal histories of political violence and what kinds of sociocultural practices enhance their resilience. A relatively new body of research suggests that the Tibetan exile community is unusually resilient (Lhewa et al. 2007; Ruwanpura et al. 2006; Sachs et al. 2008; Terheggen et al. 2001). These studies cite testimony from Tibetan refugees who claim their religion allows them to thrive. But the working hypothesis that a Buddhist way of life promotes resilience in the context of political violence and forced resettlement remains poorly documented. In this article, I explore four related themes: (1) the cultural utility of "trauma" as a category among Tibetan refugees; (2) how Tibetan interlocutors in this study tend to view distress; (3) why the Tibetan concept of resilience is linked with spaciousness and flexibility; and (4) how these exiles_monastics and laypeople alike—utilize a Buddhist practice known as lojong, or "mind training," to generate flexibility, transforming their relationship to distress. I argue that these are important factors that shape experiences of coping and promote resilience among Tibetan refugees.

Many Tibetan refugees argue that even with catastrophic events such as territorial displacement, torture, and imprisonment, ultimately it is the way one interprets negative events that causes one to suffer. In other words, suffering comes from one's own mind (not external events). It is in transforming one's view or relationship to suffering where successful coping and a bolstering of resilience transpire. Some psychological anthropologists (e.g., Csordas 
1983; Seligman and Kirmayer 2008) argue that healing often comes from a reframing or reorientation towards suffering. However, in many cases this reframing is implicit or symbolic, as in various types of religious healing (Lester 2005; Seligman 2010). Here, Tibetans are quite explicit in their goal: to mitigate suffering, one needs to reframe one's relationship to adversity and negative emotions. The end result of this reframing is a greater sense of space and flexibility within the mind-qualities Tibetan interlocutors argue are important features of resilience.

\section{Field Site and Research Methods}

Some 150 thousand Tibetans currently live in the neighboring countries of Bhutan, Nepal, and India, with approximately 94 thousand of this total in India (Central Tibetan Administration 2012). Tibetans began escaping to Dharamsala, a town located in the foothills of the Himalayas in the Northern Indian state of Himachal Pradesh ten years after the Chinese first invaded Tibet in 1949. But while the exile community is well established, India does not formally recognize the Tibetan government-in-exile as a legitimate political body. Tibetans come to India for a variety of reasons including: education and economic opportunities, cultural or religious persecution, to join a monastery/nunnery, and to meet the Dalai Lama (Sachs et al. 2008). Many Tibetans come to the exile community destitute and uneducated; some have been political prisoners and survivors of torture. While Tibetans migrate to growing exile communities for a variety of reasons, Dharamsala remains a hotbed for political refugees. There is a strong connection between political activism and religiosity in Tibet; indeed, many current and ex-political prisoners are monks and nuns.

This article draws upon 14 months of ethnographic fieldwork conducted in Dharamsala between 2011 and 2012. The aim of the study was to investigate how members of the Tibetan exile community cope with adversity, identifying which factors seem most salient in strengthening resilience. The pace of life in this community is slow and relaxed; one can easily walk across the small town in 15 minutes. Located in the foothills of the Himalayas, Indian and foreign tourists alike flock to upper Dharamsala (also known as McLeod Ganj) to escape the hot, crowded, busy streets of India. I lived in a small Tibetan-owned flat, which was walking distance from the Dalai Lama's residence.

While living in this community, I conducted extended participant observation in health clinics, social service organizations, political meetings, religious teachings, and community spaces. Much of my data was collected through everyday interactions, joining Tibetan neighbors and friends for meals, shopping, and accompanying them on daily visits to the Dalai Lama's temple-the heart of Dharamsala where many community members gather to practice and socialize. Alongside participant observation, I conducted semistructured interviews with 80 Tibetans to better understand how in practice exile members cope with adversity. Within this sample, 58 were community members who had experienced a range of difficulties in Tibet and during their subsequent journeys into exile, and 22 were expert key informants who helped me to understand the variety of help-seeking practices in Dharamsala. 
Community sample participants' ages range from 17 to 84 years old and includes equal numbers of men and women. Half the participants are "new arrivals," meaning they left Tibet less than five years prior to my arrival and half had been living in exile for a longer period. To capture the diversity within the greater Dharamsala area, home to 13 monasteries and four nunneries, the community sample includes equal numbers of monastics and laypeople. Participants were recruited through personal contacts and modified snowball sampling techniques. Semistructured interviews within this sample were conducted in Tibetan and focused on how community members understood and coped with difficulties in their lives. To avoid potential bias, participants were not prompted to discuss Buddhism, but rather they were asked open-ended questions about leaving Tibet and the resettlement process. If participants mentioned that religion helped them cope, this topic was explored in more depth.

Expert key informants were individuals whom community members visited for help in times of difficulty. The sample includes a group of religious practitioners, such as high lamas, oracles, and lay tantric practitioners (ngagpas) $(\mathrm{n}=9)$, and a group of medical experts and social service providers such as allopathic doctors, traditional Tibetan doctors, nurses, and leaders of community organizations $(n=13)$. Key informants were recruited using purposive sampling procedures to capture a cross-section of "helpers" in the community. These semistructured interviews focused on local idioms of mental distress, as well as coping methods and help-seeking behaviors. Interview guides also engaged an open-ended discussion related to resilience in the exile community.

All interviews were transcribed in Tibetan by my local research assistant. After transcription, my assistant and I collaboratively translated each transcript into English. Using Atlas.ti software, I used open coding procedures to analyze field notes and interview transcripts, generating key themes related to resilience and coping.

\section{The Cultural Utility of "Trauma" as a Category in Dharamsala}

Many important thinkers over the last few decades have contributed to a growing literature on the historical and social construction of trauma. Considered by some to be "the great psychiatric narrative of our era" (Luhrmann 2010:722), there is an abundance of trauma studies across the social sciences and humanities. Anthropologists in particular have critiqued the universalizing of post-traumatic stress disorder (PTSD), showing how while trauma is taken to be a natural human experience, it is a relatively new concept brought into existence at a particular moment in history (Fassin and Rechtman 2009; Young 1995).

This section explores the utility of trauma concepts in Dharamsala. I show how while the concept of trauma is elaborated through institutional and public manipulation of traumatic images and narratives as a political device, Tibetan community members seem to experience distress in a way that is not analogous to biomedical frameworks. These findings complicate the notion that trauma is a universal outcome of political violence. 
We know from social theorists (e.g., Bourdieu 2000; Foucault 1965; Goffman 1961) that psychiatric categories are not sufficiently perpetuated merely by labeling individuals, as such. For a mental disorder to become normalized within a society, individuals must come to identify with, and phenomenologically experience oneself as, a "depressed," "psychotic," "traumatized," or otherwise-categorized person. Hacking $(1995,1998)$ refers to this interplay between self and society as a "looping process," whereby individuals change their behavior to match a culturally constituted category. The self is shaped largely by the responses of others; the more the category is recognized in oneself (by others), the more one identifies with the category. Building on Hacking (1995), Seligman and Kirmayer have described trauma as products of "bio-looping"; an exchange between patterns of attention and information processing with cultural scripts (2008:50). Their study draws attention to the work of culture in that without feedback and reinforcement from the social world, the loop does not continue.

The Tibetan exile community acts as an interesting case study in this regard. While traditional Tibetan idioms of mental distress do not, in many respects, resemble Western notions of "trauma," the exile community is engaged in an international human rights campaign —an endeavor that depends on exposing "traumatic experiences" among Tibetan people. Tibetans in exile are eager to gain support from the international community who may question the veracity of human rights violations at the hands of the Chinese government. Yet, speaking openly about mental distress is not consistent with Tibetan cultural values. Rather, people support one another by encouraging a "letting go" of negative emotions and distress. In a sense, the "looping process" of trauma seems to lose, rather than gain, momentum through social interaction.

Within biomedicine, trauma is understood as a specific set of reactions to a stressful event (e.g., nightmares, hypervigilance, flashbacks), and importantly, it is marked by prolonged debilitation and impairment. One criterion for PTSD as listed in the DSM-IV is that symptoms last for at least six months following exposure to a troubling event. As Young remarks, "PTSD is a disease of time. The disorder's distinctive pathology is that it permits the past (memory) to relive itself in the present, in the form of intrusive images and thoughts and in the patient's compulsion to replay old events" (1995:7). Within the Tibetan psychiatric nosologies, there is no particular gloss for such a disorder. ${ }^{1}$ This is not to say that refugees never experience prolonged and intractable mental distress, but the production and cultural value of "trauma," as a category, or mode of experience, is not particularly salient among Tibetans.

For example, when a group of nuns were gathered by Jack Saul and colleagues to discuss their torture experiences, many remarked they had never shared their stories, despite living closely together in the nunnery. They knew of a shared, common history, but there was no impetus before the gathering with foreign researchers to discuss and process their torture experiences ${ }^{2}$ (personal communication with author, April 1, 2010). Many researchers are also surprised by what Tibetans consider most difficult about the Chinese occupation. When asked to rank stressful life events, Tibetan refugee respondents 
in two different studies stated that witnessing the destruction of religious temples and being forced to denounce one's religion was more upsetting than even imprisonment and torture (Terheggen et al. 2001; Sachs et al. 2008), raising important questions about trauma appraisal.

Upon visiting the Central Tibetan Administration's Department of Health, I was told there was a clinic for torture survivors. However, when I later visited the clinic, I found that in the last year they had provided services (a few home visits) to only two Tibetan torture survivors. In my many formal and informal discussions with community members, the clinic was rarely mentioned. Instead, a prominent community organization started by and for ex-political prisoners was considered the best place for torture survivors to seek help in the form of housing, material assistance, and language or vocational training. "Why would they go to the hospital?" asked a young woman named Lhamo. "They are not sick!" The organization is social and political in nature, rather than clinical.

In addition to providing services, the organization is actively involved in the international human rights campaign. Inside the center, one finds the walls covered by gruesome photographs of torture victims and corpses-bloodied and disfigured. These images displayed as "proof" for visitors ask them to bear witness to the bloodshed; they also galvanize political sensibilities within the community. Similar photographs are displayed at the new arrivals center, where the Tibetan government-in-exile provides medical services and housing for new refugees. Political posters are strewn around town and local restaurants host talks with ex-political prisoners, aimed at educating young foreign travelers. At these talks, Tibetans give graphic accounts of their imprisonment, rallying support for the Tibetan cause. As Adams asserts, "[f]irsthand accounts 'count' for everything in human rights discourse" (1998:82). But as she goes on to argue, the Tibetan experience of suffering is in many cases inconsistent with human rights discourse (1998), particularly insofar as cultural beliefs like karma predominate the experience of difficult life events. The testimony practices found among Tibetan political activists appears in stark contrast with the customs of everyday life.

Anthropologists have described similar phenomena elsewhere. For example, Breslau (2000), in his study of international mental health aid in Kobe, Japan following the earthquake, describes how foreign mental health professionals encouraged the practices of testimony and debriefing, despite the dissonance with local concepts of recovery. Likewise, McKinney found that among mental health services in the United States and Denmark aimed at helping survivors of political violence from around the world, where helping people find their "trauma story" seemed to be the predominant therapeutic form. It is assumed, she argues, "that every client holds some sort of traumatic memory, a memory that by definition disrupts the continuity of identity or self " (2007:270). While biomedical perspectives frame the acts of "telling," "processing," "debriefing," and "testifying" to be inherently therapeutic, these notions are in some ways antithetical to Tibetan notions of healthy coping. 


\section{Tibetan Frames for Mental Distress and the Cultural Logic to "Let it Go"}

In this section, I explore how Tibetans actively deploy culturally meaningful frameworks to disrupt the bio-looping process that might otherwise produce trauma from experiences of political violence. I describe how my Tibetan interlocutors understand mental distress and why there is a push to "let go" or "transform" disturbing emotions. Seeing these emotions as impermanent and changing, they are reticent to dwell on distress, which seems only to stagnate or prolong it.

A number of studies find that despite a high prevalence of potentially traumatizing events (imprisonment, torture, religious and cultural persecution, mass displacement), rates of psychological distress are extremely low and that coping activities (primarily religious) appeared to mediate the psychological effects of trauma exposure (Holtz 1998; Ketzer and Crescenzi 2002; Lhewa et al. 2007; Ruwanpura et al. 2006; Sachs et al. 2008). Despite the robustness of these findings, some question whether these Tibetan respondents are truly "resilient" or if they simply avoid identifying symptoms of mental distress. Researchers note that Tibetans often do not express much of their physical and emotional pain, even when asked directly (e.g., Servan-Schreiber et al. 1998). Some scholars are skeptical about just how genuine these low levels of psychological distress might be, arguing there is response bias (Sachs et al. 2008) — seen as the only logical explanation for calm and cool recounting of severe adversity, such as torture and imprisonment.

Other, more critical researchers, such as Makley (2005) in her account of why Tibetans in Labrang avoid "speaking bitterness" in relation to the Chinese occupation of Tibet, assert that purposeful omission or nondisclosure of traumatic experiences should be viewed as an "alternative practice of time" where a reshaping of cultural memory is at once an act of self-protection and political resistance. Makley argues that to view a Tibetan propensity to avoid recounting stories of political violence as "repression" is to grossly misrepresent cultural values and the function of memory.

Here, too, rather than ascribing to binary reasoning (e.g., either Tibetans are extremely resilient and "bounce back" in the face of difficulty or they repress emotions and deny pain), I take a more nuanced look at processes of coping and resilience, coming to see resilience as a learned process and moral practice. Tibetans actively deploy shared cultural understandings, often infused with Buddhist doctrine, to reframe the mental distress associated with loss, violence, and other distressing experiences. These cultural practices encourage letting go of distress rather than holding on to or solidifying it.

Many Tibetans in Dharamsala rely on Buddhism to cope with difficulty. A good example is the way that Tibetans tend to view suffering itself. In his first teaching, the historical Buddha declared that life is marked by suffering (the first Noble Truth); in fact, it is the defining feature of samsara, an endless cycle of rebirth fueled by the mind's misperception of reality. But while pain is inevitable, Buddhism teaches that suffering is not. As Janes found in Tibet, pain can transform "into an opportunity for revelation ... the task for people becomes 
not how to avoid suffering or how to recover from it, but rather, how to suffer gracefully, employing and manipulating symbolic devices available for doing so" (1999:392). As one geshe $e^{3}$ explained, "it is important to know that samara is in the nature of suffering. If you know this, you are already prepared and ready to cope with suffering. You expect it."

How does expecting suffering help promote resilience? The expectation of suffering is connected inextricably to the concept of karma, a highly complex system of cause and effect. If asked to explain karma, most Tibetans will suggest consulting a high lama. Yet at the same time, it shapes the ontological worldview of Tibetans regardless of their religiosity. For people living in North America, when something devastating occurs, they typically ask: "why me?" Tibetans do not ask this question. One may struggle with what happens in one's life, but ultimately karma acts as an ordering principle of reality, allowing people to accept what life brings them.

A number of my interview participants lost friends and family members in a major earthquake in Tibet in 2010. As one soft-spoken young man, Tashi, ${ }^{4}$ age 24 , told me:
Most of my family died; seven of us died. Only me and my younger brother survived. This is karma. It was their karma to die and it was our karma to live. There were also many Chinese killed. The Chinese were frantic and wailing in the streets. Tibetans were much calmer. I don't think we were any less sad, but we accept death as a part of life. We also believe that it does not help the situation to become very upset. This can prevent those who died from moving on through the bardo [intermediate state between death and rebirth], and it doesn't help us either. My brother and I joined some others from our county and made prostrations to Lhasa [some 750 miles away]. We made offerings along the way and dedicated the merit ${ }^{5}$ [good karma], to our family. I felt at peace knowing that we were doing something to help our loved ones.

There is a sense that life circumstances are earned. Karma is not viewed as a particularly "religious" topic; it simply explains how the world works. Negative events in the present are understood as the result of negative actions in the past. To fully understand how Tibetans cope with suffering, it is essential to recognize that their view extends much wider than the present; what happens in this lifetime is only one small piece of a much larger picture of past and future lives.

A Russian colleague working in Dharamsala, Kuba Bobrzynski, once told me he met a Tibetan man in his seventies who had his arms and legs bound while being held at a Chinese prison. With time he learned to pull his hands out of the binds. But after some time he rebound his own hands thinking that otherwise he would not be able to "repay his karma" if he finds a way to suffer less (letter to author, July 3, 2012). While Tibetans do not typically seek out pain to purify karma, many maintain daily practices aimed at purifying negative karma and generating merit (e.g., circumambulating stupas and temples, prostrations, reciting mantras, making offerings), and older generations as they draw nearer to death often devote the remainder of their lives to these practices. They also view difficult life events as an opportunity for purification. Friends and relatives console one another 
with reminders that karmic seeds or imprints have been purified. "It is over now," they say. The seeds are "extinguished," and one is advised not to ruminate or cling to negative emotions. Disturbing emotions are thought to only reproduce suffering by strengthening karmic imprints, particularly those that lead one to perform negative actions. One essentially recreates a propensity to generate negativity.

Life's difficulties are painful, but in a sense they are not wholly unwelcome. Once my wallet was stolen in New Delhi; when I mentioned it to my friend, Yangzom, she replied cheerfully: "oh, that's good! You purified the negative karma you had with the thief." This perspective stems in part from the Buddhist ideal of achieving enlightenment, which is more a process of clearing away than needing to acquire something. Even among Tibetans who cannot explain the metaphysical workings of karma, most seem to have a built-in sense that difficulties in life also contain great potential and can be weathered to benefit.

It is understood that the mind (sem), more appropriately translated as "heart-mind," needs to be kept stable and calm, despite adversity. Elsewhere, anthropologists (e.g., Craig 2012; Desjarlais 2003; Kohrt and Harper 2008) describe how negative events are potentially dangerous - not in and of themselves-but in terms of how they occasion intense or uncontrollable emotion to arise. In Dharamsala, those who experience difficulty are advised to quickly let go of disturbing feelings; a psychologically healthy person is not someone who assertively expresses a range of feelings. Rather, Tibetans tend to view negative emotions as toxic.

Many Tibetans do not readily talk about their problems. This is, in part, because they believe that talking about them too much will only prolong suffering, making things worse. But there is also tremendous value in being humble, perhaps over and above other desires, such as voicing one's concerns. Talking to others about one's problems is seen as something one does when one is young and not yet mature enough to cope. When I asked interview participants to describe how they coped with problems, only a small handful mentioned coping through sharing problems with others. Those who did tended to be young women under the age of 25 . This does not mean that seeking social support is never a coping strategy. But it suggests that talking about one's problems is not highly valued.

Many community members that I consulted also explained how negative emotions cause illness-particularly if they are pervasive. For example, Sonam, a 60-year-old mother of four explained: "this back pain, my kidney problems. It comes from too much worry and crying. When my husband died back in Tibet I had to care for my children by myself. We did not have enough food. I worried and worried for many years, so now I am sick a lot.” But while mental distress can lead to illness, problems related to the mind are often seen as more moral than medical.

Within many Tibetan communities, overt mental illness is often attributed to spirit harm (Clifford 1994; Samuel 2007), for which one needs the help of a lama. Indeed, approximately $94 \%$ of my interview participants stated they would visit a lama before a doctor to treat 
mental distress. However, some religious practitioners will do a "mo," or divination, and determine that individuals with mental distress should visit a doctor-often when they suspect a rlung, or "life-wind" imbalance. And yet even medical disorders, such as rlung (pronounced "loong") are based on moral concepts of personhood (Adams 1998; Clifford 1994; Janes 1995; Millard 2007).

A number of anthropologists have written on rlung disorders as an emerging "epidemic" in Tibetan communities (Adams 1998; Janes 1995; Prost 2006), suggesting that traumatic distress (particularly political violence) is expressed by this culturally constituted category of illness. It can cause dizziness, insomnia, chest pain, syncope, vertigo, sadness, disorganized thinking, and psychosis. One is said to be at risk for developing rlung disorders if one's negative emotions are strong. Some inherit a propensity for the disorder in past lives, putting them at higher risk (Adams 1998). This is not unlike nervios among Latin American populations where a predisposition for "altered nerves," if exacerbated by prolonged distress, can lead to psychosis and other severe mental illness (Hinton and Lewis-Fernandez 2010:212). Also among Khmer trauma survivors, Hinton et al. (2002) found a high prevalence of complaints related to a "weak heart," which seemed to be worsened by anger, worry, or other psychological disturbances.

Research elsewhere describes how "excessive thinking" is a local idiom of distress across a number of non-Western contexts (e.g., Yang and Singla 2011). In Dharamsala, young monks and nuns studying for philosophy exams are thought to be at risk for rlung disorders because of "thinking too much." My research assistant became very concerned when I decided to study philosophy at one of the monasteries. "But, Sara-la, ${ }^{6}$ you already do too much thinking!" he cried. "You cannot study debate philosophy. You will become ill." There is a strong sense that one needs to maintain a calm inner and outer environment to stay healthy. Overthinking, excessive emotionality, as well as volatile environmental conditions can all lead to problems with rlung. In my interviews, nearly everyone talked extensively about how food and weather were difficult upon arrival to India. As Adams explains:

winds outside the body are the winds inside the body; they are of the same substance and potentiality-effects outside are effects inside... Whether one experiences winds as climatic change, political or family trouble, or the fruition of karma from past lives, these experiences are understood not simply as internal responses to external conditions but also as internal imbalances manifesting as external distressors .... For example, when Tibetans talk about foods and job frustrations as similar disruptions to their winds, they are telling us that, in terms of bodily experience, these two things are in the same category. [1998:88-89]

While imprisonment, torture, and displacement are more severe in degree, they are understood to be just like any other potential disturbance (e.g., bad food, bad weather), which can make it difficult to control the mind. The extent to which one experiences mental distress depends on the reaction to the event; in other words, suffering can only come from within. As my elderly neighbor told me, a Tibetan proverb says: "self is the protector of itself." 
Because losing control of one's emotions can lead to illness and the generation of negative karma, Tibetans have great motivation to recover quickly in the face of adversity.

\section{Flexibility, Space, and the Building of Resilience}

Recent studies in transcultural psychiatry have shown how mental health interventions that promote greater flexibility within the mind can help patients manage anxiety and trauma (Hinton et al. 2012; Hinton et al. 2013; Kashdan 2010). Kashdan (2010) defines psychological flexibility as the ability to distance oneself from current or habitual mindsets and to consider other possibilities; he also argues that flexibility is absent or diminished in many forms of psychopathology. Hinton and colleagues developed "Culturally Adapted Cognitive Behavioral Theory (CA-CBT)" which asks patients diagnosed with PTSD to replace distressing thoughts with culturally relevant images while making "self-statements of flexibility" (2012:349; e.g., "May I flexibly adjust to each situation just as the lotus flower is able to adjust to each new breeze"). The common theme in these studies is that a flexible mind-one that accommodates change, openness, and new possibilities—allows one to transform suffering.

In the current study, when asked to identify the characteristics of a resilient person, participants described someone who is compassionate, humble (does not exaggerate their problems), and has a flexible, vast, and spacious mind. I suggest that what some researchers have referred to as the Tibetan propensity not to disclose emotion, or to repress, may actually more closely resemble what they call "broad thinking" (sems pa chen po). Conscious about not exaggerating or solidifying negative emotions, many community members argue this is an effective way to approach problems. As one older woman named Dekyi explained:

some think, 'oh, this is a small problem and it is only natural to experience some difficulties in life.' Then they just ignore the problem and move on. These people are very skillful because they don't disturb others with their many problems. It doesn't mean they are like cows who feel nothing! But they don't disturb or harm others when trying to cope. Anyway, whether people can cope well or not depends on individual ways of thinking.

Comments such as "just ignore it," "try to move on," or "it's not a big problem," is not about repressing the problem but about not "buying into" harmful emotions. There is a strong sense of not taking oneself or the situation too seriously.

In fact, many high lamas-perhaps best exemplified in the Dalai Lama's exuberant, joking demeanor-teach on the benefits of humor. Dzigar Kongtrul states:

having a sense of humor doesn't mean laughing or being cheerful all the time. It means seeing the illusory nature of things-and seeing how, in this illusory life, we are always bumping into the very things we meticulously try to avoid. Humor allows us to see that ultimately things don't make sense. The only thing that makes sense is letting go of anything we continue to hold on to. (2009:131) 
To return to the notion of trauma as a "looping" effect, holding things lightly may be an instance where suffering loses its momentum. With a relaxed or even humorous stance towards suffering, resistance to the feelings lessen-the difficult situation may remain, but a flexible attitude helps one cope. Hacking (1995) emphasizes that the "trauma loop" is fueled by feedback from the social world. When Tibetans "minimize" their pain, others do not accuse them of repressing their feelings. Rather, they applaud their humility and broad-mindedness.

A common theme was the notion of maintaining mental stability or equilibrium-often more highly valued than expressing emotions. Tibetans living in India are often badly treated by Indian visa offices and government officials, and they never know if their documents will be renewed or denied. On a few occasions I witnessed such discrimination. But rather than becoming very upset or hostile, they remarked how important it was to maintain equanimity. "It is not worth it, getting upset," a woman named Drolkar explained. "It does not help. It only hurts one's own mind-we are the ones who lose out if we become upset."

Certainly, not all Tibetans maintain calm equilibrium in the face of difficulty. During interviews, I asked participants to describe why some people do better than others in difficult situations. A 54-year-old man named Wangdu who came to India six years ago said the following:

Two people may have the same problem yet feel very differently. Some people even if they have many problems, say nothing, but they are very stable and cope easily with their problems. I think the people who don't say anything are happy inside. It is not important to express every problem you have. It is more important to remain stable no matter what is happening. The reason people cannot deal well with problems is that they don't have the quality of spaciousness or vastness in their minds. When that person encounters any problem it exhausts everything and they have no space to deal. They become unhappy and sick. The person who is ready to face difficulties will not have many problems even if they are a political prisoner sentenced to 17 or 18 years, or even a death sentence. They can deal with these problems because they have the patience to cope with anything. If Tibetans are compared with people from other countries, they can deal with things much better. Around here there are many ex-political prisoners. Their bodies are very weak and exhausted because they were tortured and beaten severely in prison. But mentally they maintain a sense of dignity and confidence. Others would become upset very easily.

Not liberally expressing one's problems was a common theme, and this was coupled with the notion that coping through changing the way you think is effective in making the mind more spacious, open, and flexible-qualities associated with resilience and well-being.

To cultivate this flexibility, instead of resisting the situation, one works to transform one's relationship to outer circumstances, even in the face of severe outer and inner chaos. Consider the following narrative from a monk: 
I was arrested in 1988. Those in prison have great suffering because they have no freedom and are put in small cells. The guards use harsh words and torture inmates relentlessly. After we die, some become hungry ghosts and hell beings. We don't know their suffering, but here on earth, the worst suffering is prison. When the youth couldn't tolerate their hunger and thirst I would give them advice according to Buddhism. Many masters of the past made great efforts to become bodhisattvas despite many hardships. When I think of this, I didn't feel my suffering in prison was very great. When I went to prison I had one small mala around my wrist. The guards asked me what I would do with it. I told them I would recite mantras. I had to stay as a prisoner, but I just thought of it as a retreat house. I was given food and other than that, all $\mathrm{I}$ had to do was practice. If we have too much food we feel sleepy; since I had only had a little food, actually this was much better for practice! I was there were for one year and was able to recite 100,000 mantras each of Guru Rinpoche and Chenrezig. There were many monks there like me, using it positively as an opportunity to practice. Some said: 'since we are monks, if we have to stay our whole lives here and die in prison then it is not really prison because we are here practicing the Dharma.' It is good to have all this suffering now in this life because then it is purified and we won't experience much later.

This passage reflects a number of typical coping strategies among Tibetans. He acknowledges, "I have to be here anyway," so he tries to accept the situation and transform his mind to think more broadly. During my time in Dharamsala, I often heard people recite the Dalai Lama's, perhaps, favorite piece of advice: "if you can't change the situation, why worry? And if you can change the situation, why worry?" The monk does not deny pain and hardship. Yet he changes his attitude or the way he relates to the situation, using his time in prison as a "retreat house." While at first glance, stories such as these may seem like internalized oppression or merely accepting one's fate. The difference seems to be the location of agency. With enough space in the mind to accommodate such thinking, one maintains his or her power even in unthinkable situations.

\section{Lojong as a Culturally Patterned Technology for Coping}

The sections above describe the desire many Tibetans have to quickly and skillfully mitigate mental distress. I have argued that negative emotions are seen as toxic and thought to only perpetuate negative karma. To avert their harmful effects, one is advised to create space in the mind. But how do Tibetan exile members generate more spacious and flexible minds when distress inevitably arises?

A common practice I observed was the use of "lojong" or "mind-training" techniques, whereby one uses Buddhist logic to deconstruct both the legitimacy and utility of negative emotions. When one becomes "stuck" in suffering, lojong is a technology used to create space and flexibility. But how does a high philosophical set of teachings from the 11th century become of use to contemporary Tibetans, including those who know little about Buddhism? I will demonstrate how these teachings have become part of the very fabric of moral life for Tibetans and argue that this perspective is an important factor in strengthening resilience. Not all Tibetans are particularly religious. But Buddhism is a central force 
in cultural life. Quite simply, practicing the tenets of lojong is viewed as a means to become a happy person. Viewing any situation as workable, the teachings help one transform suffering.

Lojong (Tib: blo sbyong), translated literally as "mind-training," was first brought to Tibet by Atisha, an Indian pandit, who received the teachings from a meditation master in Indonesia. But the teachings are often associated with the Kadampa master, Chekawa Yeshe Dorje (1102-1176), who is said to have stumbled upon the following lines of an open book:

Give all victory to others;

Take defeat for yourself

Chekawa later wrote what is considered one of the most important works in the Tibetan Buddhist cannon: The Seven Points of Mind Training, a set of teachings routinely taught to lay practitioners. In a decidedly "fake it, till you make it" style, the lojong practice coaches ordinary people to respond to adversity as if they were bodhisattvas, realized beings whose sole concern is the well-being of others (Kongtrul 2005).

The teachings, despite their profundity, are written to appeal to common sense. They contain a set of 59 "slogans" (the traditional translation) — a pith instruction one can call upon in moments of discomfort. These are aimed at cultivating two qualities: "emptiness" as the correct view of reality and compassion. Buddhist sutras describe these qualities as two wings of a bird-without both wisdom and compassion, the bird cannot fly. The lojong teachings show that putting others before self (like bodhisattvas) is not recommended just to "be nice," but rather it is seen as the most efficacious way to realize the empty and impermanent nature of reality. It is also considered the supreme method for being happy. Paradoxically, lojong coaches that to find happiness, we should "drive all blame into oneself." This does not stem from a sense of ethical obligation; rather, it is utilitarian for those seeking enlightenment. Perhaps counterintuitively, Tibetans argue that wishing happiness even for one's enemies "liberates" one from disturbing emotions. I often heard the Dalai Lama and other important lamas instruct community members to forgive the Chinese government-and not necessarily for the sake of the Chinese, but because anger and resentment are harmful to oneself.

There is also a meditation practice connected to lojong known as tonglen, the practice of "giving and taking," where one wishes to take on the suffering and misfortunes of others. The practitioner imagines breathing in illness, evil, and pain in the form of black tar or smoke, absorbing it into his or her heart and rejoicing that now others are free from misery. One then breathes out freshness, space, and light, which are absorbed by all sentient beings without discrimination. In fact, there is even particular emphasis on practicing for those one most dislikes as a form of "training." While the actual tonglen practice is very advanced, it is used even by ordinary people, particularly in difficult situations such as being with a dying relative. A young Tibetan psychologist (the only mental health "professional" in 
Dharamsala ${ }^{7}$ ) confided in me one afternoon: "When I don't know what else to do for people sometimes I just silently practice tonglen." Others mentioned it as an ideal, or a practice that exemplifies the mind-set many wish to possess. Those who can put "others before self" are considered exceptionally resilient-indeed this way of thinking is at the very pinnacle of emotional health for Tibetans.

The key feature of lojong-style advice is to shift from criticizing or changing the external situation to turning inward, seeing one's own samsaric mind as the root of suffering. "Even if they don't know anything about Buddhist philosophy," explains Geshe Dawa, "when people begin to see their problems in terms of their own minds, and not out there somewhere, they develop a broad and vast view. And this reduces suffering." He offered the following as an example:

I went to Portugal and met a girl who broke up with her boyfriend. I told her because you are young you will find another boyfriend! I told her that she shouldn't contact the ex-boyfriend or try to meet him again; just let it go. Then she said that they work in the same office. I asked her if she can change her job. She said that it was the best office and she had an excellent salary. As they worked together in the same office she would see him speaking with other girls and have even more suffering. Then I told her that I would teach her to practice lojong, which is something I used in prison. I explained that when I was very young in Tibet I caught some flies and put them inside a jar. I played with the jar and listened to the jar as if it was a radio with the flies buzzing. I put many flies in the same bottle. When I think back to this time, it is the same as prison. A few flies even died in the jar. I thought that really, it is my karma to stay in prison. This helped me to deal with suffering because I realized that I created it myself. Actually, I had a great opportunity to experience a lot of suffering, which meant I was purifying obscurations [karma]. Thinking like this, my mental problems gradually diminished. Like this, in many past lives, you must have done something negative to your boyfriend. If you did negative actions, then this is the result. If you experience the result now, you won't get this suffering later. The best would be if you could wish happiness for your ex-boyfriend. You could even think, okay, just like me, the new girlfriend just wants to be happy. If you can think very deeply then you will see it is not so difficult. One day she told me she no longer had these problems, even working side-by-side with the ex-boyfriend.

This example is interesting because it contrasts conventional worldly advice with lojong. Perhaps because she was a foreigner, he begins by making suggestions on how to change the external environment. When he switches to lojong, there is a shift from problematizing the situation itself to the girl and how she creates her own suffering. The moment of success comes when she does not have to modify the situation because instead, she has modified her thinking about the situation. This also shows how Tibetans use lojong-informed advice in a rather informal way. Certainly most Tibetans do not walk around repeating lojong slogans to one another. But rather, this manner of thinking (to put others before self and to transform suffering) permeates cultural sensibilities. 
With some 30 thousand monastics in exile (Central Tibetan Administration 2012), I was interested in both the "high religion" of monks and nuns (Ortner 1989) as well as the more "vernacular" practices and beliefs of lay people. Generally only monastics engage in meditation and philosophical study of scriptures, whereas most lay Tibetans practice Buddhism through devotional practices (Harvey 2001). But as Primiano cautions, scholars who juxtapose "official” religion with "folk, 'unofficial,' or 'popular' ... imply that religion somewhere exists as a pure element which is some way transformed, even contaminated, by its exposure to human communities" (1995:38-39). Taking heed of this pitfall, rather than conceptualizing Buddhism as something static and unchanging, I account for its dynamic and contextual influence. The question of how Tibetans come to incorporate lojong into everyday beliefs is an important one.

Anthropologists have long been interested in the question of "internalization"-that is, how and why particular cultural ethos and beliefs are adopted by individuals (Carlisle 2008; Obeyesekere 1990; Spiro 1997; Throop 2003). Shore (1996) argues that through ritual and repetition, semantic codes are created to interpret events. Many Tibetans-monastic and lay alike-learn about cultural values through anecdote and allegory. Religion scholars, such as Hallisey and Hansen (1996), argue that stories and narratives are typical means for shaping moral life across Buddhist cultures. This style of teaching is found not only in Buddhist scriptures but also in everyday life. Many lamas with whom I visited answered my questions through story-telling. Likewise, older people give younger generations advice through allegory. Many of these stories and anecdotes describe great bodhisattvas-realized beings who work only for the benefit of others. There is also particular fondness for trickster yogis who act in seemingly outrageous ways but through "skillful means" are actually working to benefit beings. Some rather lovingly refer to the Kagyu tradition (one school of Tibetan Buddhism) as the "mishap lineage": through great wisdom and compassion, they use chaos and confusion as an opportunity to "wake up" (Trungpa 2009). Such tales inspire courage, acknowledging that it is in some sense outrageous to put others wholly before self. But while most people do not meet the ideal of acting tirelessly for others (this would be to make the mistake of romanticizing Tibetans that Donald Lopez [1998] so wisely warned against), these stories show what Tibetans value most.

Another important way the lojong teachings are learned in Dharamsala is more direct, through religious teachings - an integral part of community life. Nearly all community members attend the Dalai Lama's frequent teachings - if only to don one's finest clothing and have a picnic with family. Lojong-style teachings on emptiness and compassion are among the most common, and they were routinely referenced in interviews, certainly with monks and nuns, but with laypeople as well. For example, a 17-year-old student named Tenzin said, "We know from attending teachings by His Holiness [the Dalai Lama] that the best way to be happy is to put others before ourselves. But he knows this is hard to do, so we should start very small." Most lay Tibetans, if asked directly, will insist they do not understand core concepts of lojong, such as emptiness, ${ }^{8}$ and yet such teachings seem to permeate cultural sensibilities to such an extent that they readily draw upon them in times of crisis. 


\section{Emptiness}

Lojong teachings are very pragmatic in nature. Since life inevitably presents difficulty, the teachings show how adversity can be used as an opportunity to generate greater wisdom (realization of emptiness) and compassion. As one lama explained, there are different ways to work with suffering which bring the same result. "All people want to have happiness," he said, "however under the influence of attachment and desire they are not happy. Some practice emptiness as an antidote to attachment and become happy; some practice compassion and cherishing others as a way to become happy." But while it is easy to imagine how practicing compassion helps one to be happy, what does it mean to practice emptiness? Emptiness, or shunyata (Sanskrit), sometimes referred to as "voidness," is taken to be the nature of reality and, indeed, the nature of one's own mind. Rather than seeing reality clearly, ordinary beings tend to view phenomena (and oneself) as permanent, unchanging, and independent. This is synonymous with "dependent origination," the notion that nothing exists from its own side; all phenomena exist only in terms of causes and conditions or dependence on other arising phenomena. This can also be thought of as interdependence. Not understanding emptiness is considered the very foundation of suffering. The Buddhadharma teaches that we resist the nature of reality and wish to solidify our possessions, our relationships, and our health-we want to make them permanent and unchanging, and when we resist change, we suffer.

When difficulty arose, many Tibetans with whom I spoke used lojong principles to try and reflect on impermanence. Reflecting on emptiness and impermanence as a way to cope with difficulty does not mean that people do not suffer. But they accept the Buddhist notion that suffering comes from the inside-from one's own mind-and not from the outside. Tashi Dolma, a 35-year-old woman who left Tibet ten years prior to my arrival in Dharamsala says:

When my mother passed away I tried to think about no-self [doctrine] and emptiness. I thought how plants look beautiful, fresh and alive in summer. However, gradually seasons change and leaves fall on the ground. Likewise, my mother was 65 years old and she had become old and reached the end of her life. There was nothing that could be done and I just accepted it. I am a refugee and I was unable to see my mother before she died. I believe this is the result of previous karma. Thinking like this was of great benefit to me. Buddhist philosophy has influenced Tibetan habits so people think about karma and impermanence, which helps them cope with problems.

In Buddhist doctrines, it is shown that both the self and external phenomena are empty and impermanent, meaning they are the result of something else-they are interdependent. The lojong teachings describe how the more one understands the relationship between emptiness and interdependence, the more compassion will naturally arise.

\section{Compassion}

Compassion is a fundamental aspect of Mahayana Buddhism, of which Tibetan Buddhism is one stream. Exemplified in the bodhisattva vow, the wish to continue taking rebirth until all sentient beings have attained enlightenment, compassion is considered the pinnacle 
of emotional health. Even scientists in the West are investigating its demonstrable health effects, hypothesizing that compassion meditation might go above and beyond stress relief (Leung et al. 2012; Lutz et al. 2009; Pace et al. 2009). Nearly all these laboratory studies show that positive effects are mediated by gaining proficiency, suggesting that increased capacity for compassion is learned. Indeed, there is a sense in the Tibetan community that one needs to train in building compassion, which monks and nuns accomplish through study and debate. The heart of many debates is to logically deduce why compassion is a natural response if one is in accordance with reality. It is not necessarily about "being nice," but about "being real." If one understands the emptiness of self and phenomena, a sense of connectedness and compassion would be the logical result.

As Ozawa de-Silva and Ozawa de-Silva note, not simply a cultural value, compassion is taken literally to be a defining feature of health and well-being. They explain, "[i]n Tibetan medicine, by way of contrast, the cultivation of compassion and empathy is seen as central to the logic of health itself, because such psycho-physical states are the very opposite of the negative emotions that give rise to the imbalances... that lead to disease" (2011:99). A mind that is compassionate and calm is more highly valued than the capacity to express a range of emotion (which is highly valued in the West).

A sense of compassion for others was a dominant theme in nearly all the stories I collected about hardship and coping. Many community members described how talking too much about their problems and dwelling on negativity is not only harmful for oneself but can also create problems for others. A young man named Sonam tells the following story.

When my best friend died on the journey to India, I was extremely sad. I was only around 22 years old, but I had studied in a monastery, so I was better equipped to deal with it. When I considered what had happened, I thought that he was the only one of forty people to have died. This was clearly the result of his karma. Therefore I tried to deal by simply accepting it, and I thought that crying and being unhappy would just make things difficult for others.

While others would expect Sonam to be sad after losing his best friend, he expresses concern that overt emotionality might harm his companions.

An important lojong strategy used to "train" in compassion involves thinking about others in one's same situation. I often observed community members coaching friends who were going through difficult times to think "more broadly" about all the others in the world experiencing similar (or worse) problems. For example, Pema, a 40-year-old woman who has lived in Dharamsala for 20 years explained:

when my mother died, I didn't really have the same coping methods, or way of thinking, that I do now. During this time I was small so didn't really understand Buddhism, although I was influenced by it. However after thinking carefully, I understood that when someone dies, there is no way to bring them back. I understood that no matter how much I cried or called my mother, she wouldn't come back, so I thought there was no benefit in doing so. Thinking like this, I consoled myself. Also, I wasn't the only 
motherless child; there were others in the same situation. I thought we were the same and gradually the suffering decreased.

Many go a step beyond just acknowledging that others are also suffering by making aspirations to take on the pain of others; particularly those who are even worse off.

Thubten is a 58-year-old street vendor who left Tibet as a monk in the 1980s. He says:

I joined a monastery in Lhasa after being in school. But because I knew how to read and write in Chinese, I had to work in the monastery office, meaning I could not attend classes with the other new monks. I had finally made up my mind to become a monk, but it almost didn't matter because I just had to sit in the office. I was very depressed. But one day I realized that if it wasn't me here, another monk would be sitting here in my place. Thinking that doing this work allowed someone else to practice the precious Dharma filled me with joy. My mind suddenly felt very spacious and I was very happy to remain in the office on behalf of the others.

The lojong teachings advise people to look at irritating or upsetting situations in life as precious opportunities. As one lama told me, "discomfort should be regarded as a great teacher. It shows you the work you need to do-where your mind is still obscured by ignorance."

Thinking of taking on the pain of others seems to give those (particularly in seemingly hopeless situations) a sense of purpose and resolve in the face of difficulty. A 76-year-old man named Jampa was hospitalized in Tibet for diabetes-related problems.

I told them, even if it meant death, I didn't want my leg amputated. If I stayed in hospital on medication, it would cost 10,000 Chinese Yuan so I never took medicine. During this time, I suffered a lot, but always prayed and recited the Medicine Buddha mantra. This benefitted me both physically and mentally. I also tried to remember that all human beings experience the four sufferings [birth, old age, sickness, death]. Since I had to experience this suffering no matter what, I took the Dalai Lama's advice and tried to be patient and cheerful. This helped make my mind more spacious. With this more spacious mind I made strong aspirations that nobody else would experience this pain, and I had strong motivation to help them if they did.

Researcher: Would you say that you were practicing lojong?

Jampa: Oh, I'm not a very good practitioner. As Tibetans we are just taught by our parents to think like this.

Jampa's comments raise an important question about identifying lojong as a coping strategy among those who may not necessarily see themselves using the practice. Most Tibetans value humility as an important virtue, so they will generally deny that they have much 
compassion or an understanding of emptiness. Even high teachers, such as the Dalai Lama, deny understanding emptiness despite giving advanced teachings on the topic.

As might be expected, monks and nuns often refer explicitly to the use of Buddhist practices in coping with difficulty, whereas many lay community members seem to draw on Buddhistinfluenced cultural values without concern for where these ethos stem. I asked an abbot of an important monastery about this tension who explained:

They might give it a different name. But thinking in this way and practicing lojong is exactly the same. If people cherish others then within the society at large, our problems lessen. The practice of lojong can be done by monastics, lay people, as well as nonBuddhists. This is the best way to solve problems. The great masters said that lojong is the source of a great city of happiness. It is good to compare ourselves with people who are worse off. We can see how easy it is to get problems in life. Even if you become very happy you should think that there is nothing to be proud of. It is simply a result of accumulating merit in a past life. Anyway, we must keep our mind very stable and equal. If something bad happens we shouldn't get so surprised. We must keep equanimity in our minds. Like this, suffering will be resolved if you can think in this way. And will also benefit others.

The principles of "mind-training" are moral in nature, but they are not merely moralistic. Rather, lojong can be thought of in rather utilitarian terms. It is a cultural practice, a technology, used to create a greater sense of spaciousness or vastness within the mind. This space within the mind allows for flexibility that helps strengthen resilience. By "flexibility" I mean that suffering and negative emotions are not taken to be so solid; it is recognized that difficult emotions are transient and will not last. The only lasting or permanent aspect of mind is buddhanature, the "primordial" nature of mind, which is empty, luminous, and free from obscuration.

From the Buddhist perspective, there is nothing one needs to acquire to become a loving, compassionate, or joyful person. Every being already has tatagathagarba (Sanskrit), or buddhanature-a mind in the nature of compassion. As Tsering Norbu, a 64-year-old man describes:

We all have buddhanature. His Holiness the Dalai Lama always reminds us of this. The problem is that we don't know it so we do all kinds of harmful actions. But underneath, just like the sun shining behind a sky full of clouds, is a vast, spacious and radiant mind. That is buddhanature. You asked me some questions earlier about what I do to cope with difficulties in my life. I am not a good practitioner. But if I were a better practitioner I would always try to meditate on my own buddhanature and the buddhanature of others. Many great lamas were thrown into prison by the Chinese. Some have been there for over thirty years. When I was in prison there was a very humble monk who always tried to help me. He advised me that when I was being beaten and tortured I should meditate on compassion for my torturers. I told him I cannot because I am not a great lama. He challenged me and said that because of my buddhanature, I can! This immense compassion exists whether I can see it or not. This gave me great confidence. 
Others, as well, mentioned that just knowing — if only intellectually — that they already have buddhanature, a mind that is stainless and pure, was a source of great strength. While for most, buddhanature remains a lofty ideal, I argue it becomes something of a "north star," an orienting principle for Tibetans in times of crisis. The understanding that negative emotions create further misery through karma, only further obscuring one's buddhanature, is a tremendous incentive to let go of suffering.

\section{Conclusion}

This article aims to contribute to the growing body of literature on cultural idioms of distress associated with political violence. By attending to the cultural specificity of this community, this work demonstrates not only how Tibetans tend to view suffering and distress, but importantly, how they work through adversity. In doing so, this study raises important questions about the utility of trauma perspectives across cultures. Rather than simply denying the existence of PTSD symptomatology, I complicate the utility of trauma perspectives. On the one hand, the Tibetan exile community, engaged in an international human rights campaign, uses personal narratives emphasizing severe trauma and debilitation. And on the other, members in everyday life seem to discourage dwelling on difficulty and sharing distress experiences.

While empirical findings suggest there is a low incidence of mental distress in Dharamsala, some scholars remain skeptical about their validity, asking whether the cultural propensity to avoid disclosing distress creates response bias. While the present study does not demonstrate that Tibetans are any "more" or "less" resilient than other cultural groups, the findings help to better understand local idioms of distress, as well as processes of coping and resilience. Specifically, my interlocutors understood difficulties in life as the ripening of karma and were reticent to generate more negative karma and risk illness by reacting too strongly. Instead, they recognized they had purified a karmic debt and tried to let go of negative emotions. To do so, there was recognition that one needed to transform one's relationship to difficulty.

The article explored how Tibetan exile members use lojong, a common practice or "technology" for managing distress. Swiftly working to challenge the utility of negative emotions, lojong transforms one's appraisal and experience of distress, reducing the longevity of suffering associated with potentially traumatizing events. As one foundational lojong slogan advises (Kongtrul 2005):

When misfortune fills the world and its inhabitants,

Make adversity the path of awakening.

These lines go beyond reminding one that suffering is part of life or instructing one to have a positive attitude. Instead, it suggests that suffering and adversity can be used to "wake up" to generate wisdom and compassion. 
The findings of this study challenge the notion that trauma is inevitable in the context of political violence. Understanding trauma as a looping process between the self and society, I show how because of cultural values (and practices based on these values), distress seems to lose its momentum. This perspective exists in stark contrast, for example, with American war veterans returning home to a society expecting PTSD-like behavior. The suffering of Tibetan people at the cultural or societal level is never denied. In fact, there is fervent political resistance and activism both in Tibet and in exile, evidenced by ongoing protests and recently, more than 100 self-immolations. Yet while stories of oppression at the cultural level are widely discussed, at the personal level, there is great incentive to quickly let go or transform distress. Tibetan community members encourage one another to move forward with confidence and dignity in spite of personal histories of violence. These stories contribute to a growing literature, which aims to understand not just those with clinical levels of distress and mental disorders but to examine fully the broad range of reactions to political violence.

\section{SARA E. LEWIS is a PhD candidate in the Department of Sociomedical Sciences at Columbia University.}

\section{Notes}

Acknowledgements. This research was funded through a Fulbright-Nehru award and the Weatherhead East Asian Institute at Columbia University. I wish to especially thank Rob Lemelson for generously supporting my first trip to the field through a Lemelson Society for Psychological Anthropology Pre-Dissertation Fieldwork Award. I also wish to thank the Condon Prize Committee, and particularly, Edward Lowe, for extensive support and guidance in the revision process. Special thanks to Kim Hopper and Vincanne Adams for reviewing earlier versions of the manuscript. And finally, an important "thank you" to members of the Tibetan exile community, and particularly my research assistant, Abo Gakyi, for your warmth and graciousness.

1. Some have argued that rlung disorders, particularly among torture survivors, are a suitable gloss for PTSD (Benedict et al. 2009). However, this gloss is problematic, in that many core features of PTSD (e.g., hypervigilance, flashbacks) are not particularly central to rlung disorders.

2. It should be noted that the group of nuns told Saul and colleagues they found the group helpful and wished to continue meeting, informally. However, during my time spent among nuns and monks (as well as lay community members), there was a decided reluctance to talking openly about personal experiences of violence.

3. A geshe is a monk (often within the Gelugpa school of Tibetan Buddhism, but the degree is also awarded in the Sakya and Bon traditions) who has studied intensive philosophy and debate for 12-20 years beyond the monastic college curriculum.

4. A pseudonym, like all names used herein.

5. Merit, or positive karma, can be accumulated and dedicated to others. The act of dedicating merit to others is thought not only to benefit other beings, but it also creates exponential merit and positive effects for the one generating it. Merit is often accumulated by offering butter lamps, food, money, prostrations, prayers, or circumambulating holy places. Many lay Tibetans practice Buddhism almost entirely through these devotional and merit-making activities.

6. Tibetans often place a "la" (Tib: lags) after one another's name as an honorific gesture. 
7. This young psychologist (age 23 with a bachelor's degree) worked at the Tibetan Torture Survivor's Clinic at the Department of Health.

8. This paradox is not dissimilar to how Cassaniti's (2006) informants in Thailand suggested she talk to a monk to understand complex, technical concepts such as impermanence and no-self. And just as these same Thai informants went on to describe how impermanence and no-self doctrine shapes their lives.

\section{References Cited}

Adams, Vincanne 1998 Suffering the Winds of Lhasa: Politicized Bodies, Human Rights, Cultural Difference, and Humanism in Tibet. Medical Anthropology Quarterly 12(1):74-102.

Benedict, Adriana Lee, Linda Mancini, and Michael A. Grodin 2009 Struggling to Meditate: Contextualizing Integrated Treatment of Traumatized Tibetan Refugee Monks. Mental Health, Religion \& Culture 12(5):485-499.

Bourdieu, Pierre 2000 Weight of the World: Social Suffering in Contemporary Society. Palo Alto, CA: Stanford University Press.

Breslau, Joshua 2000 Globalizing Disaster Trauma: Psychiatry, Science and Culture after the Kobe Earthquake. Ethos 28(2):174197.

Carlisle, Steven G.

2008 Synchronizing Karma: The Internalization and Externalization of a Shared, Personal Belief. Ethos 36(2):194-219.

Cassaniti, Julia

2006 Toward a Cultural Psychology of Impermanence in Thailand. Ethos 34(1):58-88.

Central Tibetan Administration 2012 Tibet in Exile. http://tibet.net/about-cta/tibet-in-exile/, accessed October 30.

Clifford, Terry 1994 Tibetan Buddhist Medicine and Psychiatry: The Diamond Healing. Delhi: Motilal Banarsidass Publishers.

Craig, Sienna R

2012 Social Suffering and Embodied Political Crisis. Hot Spot Forum, Cultural Anthropology Online. http://culanth.org/?q=node/536, accessed April 11,2012 .

Csordas, Thomas

1983 The Rhetoric of Transformation in Ritual Healing. Culture, Medicine and Psychiatry 7(4): $333-375$.

Desjarlais, Robert R.

2003 Sensory Biographies: Lives and Deaths among Nepal's Yolmo Buddhists. Berkeley: University of California Press.

Fassin, Didier, and Richard Rechtman

2009 The Empire of Trauma: An Inquiry into the Conditions of Victimhood. Princeton, NJ: Princeton University Press.

Foucault, Michel

1965 Madness and Civilization: A History of Insanity in the Age of Reason. New York: Vintage Books.

Goffman, Erving 1961 Asylums: Essays on the Social Situation of Mental Patients and Other Inmates. New York: Anchor Books.

Hacking, Ian

1995 The Looping Effects of Human Kinds. In Causal Cognition: A Multi-Disciplinary Debate. Dan Sperber, David Premack and Ann James Premack, eds. Pp. 351-383. New York: Oxford University Press.

1998 Mad Travellers: Reflections on the Reality of a Transient Mental Illness. London: Free Association Books.

Hallisey, Charles, and Anne Hansen

1996 Narrative, Sub-Ethics, and the Moral Life: Some Evidence from Theravada Buddhism. Journal of Religious Ethics 24(2):305-327.

Harvey, Peter 2001 Buddhism. New York: Continuum.

Hinton, Devon, Susan Hinton, Khin Um, Audria Chea, and Sophia Sak

2002 The Khmer "Weak Heart" Syndrome: Fear of Death from Palpitations. Transcultural Psychiatry 39(3):323-344. 
Hinton, Devon E., and Roberto Lewis-Fernandez

2010 Idioms of Distress among Trauma Survivors: Subtypes and Clinical Utility. Culture, Medicine and Psychiatry 34:209-218.

Hinton, Devon E., Edwin I. Rivera, Stefan G. Hofmann, David H. Barlow, and Michael W. Otto

2012 Adapting CBT for Traumatized Refugees and Ethnic Minority Patients: Examples from Culturally Adapted CBT (CA-CBT). Transcultural Psychiatry 49(2):340-365.

Hinton, Devon E., Vuth Pich, Stefan G. Hofman and Michael W. Otto

2013 Acceptance and Mindfulness Techniques as Applied to Refugee and Ethnic Minority Populations with PTSD: Examples from "Culturally Adapted CBT.” Cognitive and Behavioral Practice 20:33-46.

Holtz, Timothy H.

1998 Refugee Trauma versus Torture Trauma: A Retrospective Controlled Cohort Study of Tibetan Refugees. Journal of Nervous and Mental Disease 186:24-34.

Janes, Craig R.

1995 The Transformations of Tibetan Medicine. Medical Anthropology Quarterly 9(1):6-39.

1999 Imagined Lives, Suffering, and the Work of Culture: The Embodied Discourses of Conflict in Modern Tibet. Medical Anthropology Quarterly 13(4):391-412.

Kashdan, Todd B.

2010 Psychological Flexibility as a Fundamental Aspect of Health. Clinical Psychology Review 30(7):865-878.

Ketzer, Eva, and Antonella Crescenzi

2002 Addressing the Psychosocial and Mental Health Needs of Tibetan Refugees in India. In Trauma, War, and Violence: Public Mental Health in Socio-Cultural Context. Joop DeJong, ed. New York: Kluwer Academic/Plenum.

Kohrt, Brandon A., and Ian Harper

2008 Navigating Diagnoses: Understanding Mind-Body Relations, Mental Health, and Stigma in Nepal. Culture, Medicine and Psychiatry 32:462-491.

Kongtrul, Dzigar

2009 Have Courage and a Sense of Humor. In In the Face of Fear: Buddhist Wisdom for Challenging Times. Barry Boyce, ed. Pp. 129-136. Boston, MA: Shambhala.

Kongtrul, Jamgon

2005 The Great Path of Awakening: The Classic Guide to Lojong, a Tibetan Buddhist Practice for Cultivating the Heart of Compassion. Ken McLeod, trans. Boston, MA: Shambhala.

Lester, Rebecca J.

2005 Jesus in Our Wombs: Embodying Modernity in a Mexican Convent. Berkeley, CA: University of California Press.

Leung, Mei-Kei, Chetwyn C.H. Chan, Jing Yin, Chack-Fan Lee, Kwok-Fai So, and Tatia M.C. Lee

2012 Increased Gray-Matter Volume in the Right Angular and Posterior Parahippocampal Gyri in LovingKindness Meditators. Social Cognitive and Affective Neuroscience, in press.

Lhewa, Dechen, Banu, Sophia, Rosenfeld, Barry, and Allen Keller

2007 Validation of a Tibetan Translation of the Hopkins Symptom Checklist-25 and the Harvard Trauma Questionnaire. Assessment 14(3):223-230.

Lopez, Donald S.

1998 Prisoners of Shangri-La: Tibetan Buddhism and the West. Chicago: University of Chicago.

Luhrmann, Tanya $M$.

2010 Review of The Empire of Trauma: An Inquiry into the Condition of Victimhood. American Journal of Psychiatry 167(6):722.

Lutz, Anotine, Lawrence L. Greischar, David M. Perlman, and Richard J. Davidson

2009 BOLD Signal in Insula is Differentially Related to Cardiac Function during Compassion Meditation in Experts vs. Novices. NeuroImage 47(3):1038-1046.

Makley, Charlene

2005 "Speaking Bitterness": Autobiography, History, and Mnemonic Politics on the Sino-Tibetan Frontier. Comparative Study of Society and History 47(1):40-78.

McKinney, Kelly

2007 "Breaking the Conspiracy of Silence": Testimony, Traumatic Memory and Psychotherapy with Survivors of Political Violence. Ethos 35(3):265-299.

Millard, Colin

2007 Tibetan Medicine and the Classification and Treatment of Mental Illness. In Soundings in Tibetan Medicine: Anthropological and Historical Perspectives. Mona Schrempf, ed. Pp. 247-283. Leiden, Netherlands: Brill.

Obeyesekere, Gananath

1990 The Work of Culture: Symbolic Transformation in Psychoanalysis and Anthropology. Chicago: University of Chicago Press. 
Ortner, Sherry

1989 High Religion: A Cultural and Political History of Sherpa Buddhism. Princeton, NJ: Princeton University Press.

Ozawa-de Silva, Chikako, and Brendan R. Ozawa-de Silva

2011 Mind/Body Theory and Practice in Tibetan Medicine and Buddhism. Body \& Society 17(1):95-119.

Pace, Thaddeus W.W., Lobsang Tenzin Negi, Daniel D. Adame, Steven P. Cole, Teresa I. Sivilli, Timothy D. Brown, Michael J. Issa, and Charles L. Raison

2009 Effect of Compassion Meditation on Neuroendicrine Innate Immune and Behavioral Responses to Psychosocial Stress. Psychoneuroendoncrinology 34:87-98.

Primiano, Leonard N. 1995 Vernacular Religion and the Search for Method in Religious Folklife. Western Folklore 54(1):37-56.

Prost, Audrey

2006 Causation as Strategy: Interpreting Humours among Tibetan Refugees. Anthropology \& Medicine 13(2):119-130.

Ruwanpura, Eshani, Stewart W. Mercer, Alastair Ager, and Gerard Duveen

2006 Cultural and Spiritual Constructions of Mental Distress and Associated Coping. Mechanisms of Tibetans in Exile: Implications for Western Interventions. Journal of Refugee Studies 19(2):187-202.

Sachs, Ellen, Barry Rosenfeld, Dechen Lhewa, Andrew Rasmussen, and Allen Keller

2008 Entering Exile: Trauma, Mental Health, and Coping among Tibetan Refugees Arriving in Dharamsala, India. Journal of Traumatic Stress 21(2):199-208.

Samuel, Geoffrey

2007 Spirit Causation and Illness in Tibetan Medicine. In Soundings in Tibetan Medicine: Anthropological and Historical Perspectives. Mona Schrempf, ed., Pp. 213-224. Leiden: Brill.

Seligman, Rebecca

2010 The Unmaking and Making of Self: Embodied Suffering and Mind-Body Healing in Brazilian Candomble. Ethos 38(3):297-320.

Seligman, Rebecca, and Laurence J. Kirmayer

2008 Dissociative Experience and Cultural Neuroscience: Narrative, Metaphor and Mechanism. Culture, Medicine and Psychiatry 32:31-64.

Servan-Schreiber, David, Brigette LeLin, and Boris Birmaher

1998 Prevalence of Posttraumatic Stress Disorder and Major Depressive Disorder in Tibetan Refugee Children. Journal of the American Academy of Child and Adolescent Psychiatry 37(8):874-879.

Shore, Bradd

1996 Culture in Mind: Cognition, Culture, and the Problem of Meaning. New York: Oxford University Press.

Spiro, Melford E.

1997 Gender Ideology and Psychological Reality: An Essay on Cultural Reproduction. New Haven, CT: Yale University Press.

Terheggen, Maaike A., Margaret S. Stroebe, and Rolf J. Kleber

2001 Western Conceptualizations and Eastern Experience: A Cross-Cultural Study of Traumatic Stress Reactions among Tibetan Refugees in India. Journal of Traumatic Stress 14(2):391-403.

Throop, Jason C.

2003 On Crafting a Cultural Mind: A Comparative Assessment of Some Recent Theories of "Internalization" in Psychological Anthropology. Transcultural Psychology 40(1):109-139.

Trungpa, Chogyam

2009 The Mishap Lineage: Transforming Confusion into Wisdom. Boston: Shambhala.

Yang, Lawrence, and Daisy Singla

2011 Use of Indigenous Cultural Idioms by Chinese Immigrant Relatives for Psychosis: Impacts on Stigma and Young, Allan Psychoeducational Approaches. Journal of Nervous and Mental Disease 199(11):872-878.

1995 The Harmony of Illusions: Inventing Posttraumatic Stress Disorder. Princeton, NJ: Princeton University Press. 